\section{Renaissance man}

\section{H. Christopher Longuet-Higgins}

Models of My Life. By Herbert A. Simon. Basic Books/Sloan Foundation Science Series: 1991. Pp.448. \$25.95.

RIDDLES, puzzles, problems - these are the stuff of Herb Simon's life, and of his autobiography, the latest in a distinguished series sponsored by the Sloan Foundation. The quizzical title, matching those of his earlier books Models of Man, Models of Discovery and Models of Thought, challenges the presupposition that a single interpretation could do justice to a whole life; and the cryptic dedication "To Dorothea, so aptly named" hints at the deep happiness that has supported his wide-ranging accomplishments.

Simon's two best-known contributions to human thought are the theory of bounded rationality, for which he was awarded the Nobel Prize in economics, and his joint work with Allen Newall and Cliff Shaw on the foundations of artificial intelligence (AI). (The theory of bounded rationality highlights the boundary conditions within which economic agents maximize their expected utility - not least their incomplete knowledge and imperfect rationality.) Simon's principal metaphor for his life is that of someone exploring a maze, making a decision at every turn; but this is also his model of the administrator making imperfectly informed decisions, of the chess player struggling against the clock, or of the computer engaged in selective search guided by heuristics. Someone able to perceive such unities might well justify description as a Renaissance Man; but Simon prefers to present himself as a mere polymath, with a number of parallel roles and interests:

Perhaps clearest is the theme of the scientist and teacher ... seeking the Holy Grail of truth about human decision making. In my case even that thread is woven of finer strands: the political scientist, the organization theorist, the economist, the management scientist, the computer scientist, the psychologist, the philosopher of science.

To these roles he adds that of the private person, family man, university politician and science adviser, and asks which of these will step forward at the call for 'the real' Herbert Simon. But by and large the book is mercifully free from Holy Grails and rhetorical questions, and Simon writes best when he is at his least self-conscious.

The book is divided into four panels (the metaphor is that of the triptych, or rather 'tetraptych'). The first portrays a mainly idyllic childhood, describes the author's undergraduate education at the University of Chicago, and closes on his twenty-first birthday in 1937. A formative experience was his attempt, with a group of teenage friends, to tame an area of wilderness and stock it with Hereford cattle. The cattle had ideas of their own and broke down every fence the pioneers constructed, to get out of the pasture. "No doubt", writes Simon, "my later deep skepticism of the a priorism of mainstream economics had some of its origins in this experience."

At university Simon switched from economics to political science. But as for international politics, "few of us spend any large part of our lives addressing the questions of peace. In my own case, I know one of the reasons: the feelings of frustration and futility that are aroused when I try to think about problems that have no visible solution." $\mathrm{He}$

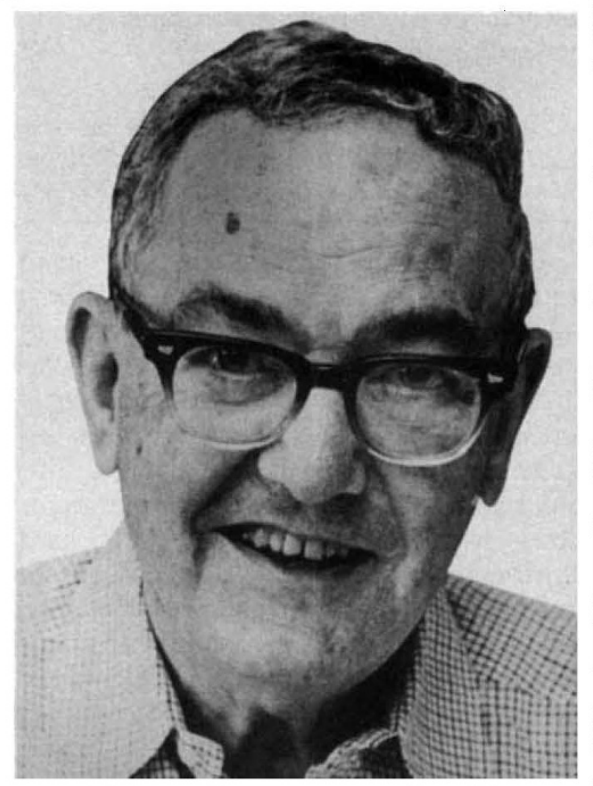

Herbert Simon - a puzzling life.

attended mathematical biology classes given by N. Rashevsky, whom he judged "rather cavalier in his attitude toward data", as a result of which he was "generally ignored by biologists". He claims that a respect for real-world data has always headed his list of scientific virtues:

. in empirical science the final test is not mathematical elegance or a priori plausibility, but the match between theory and data. I certainly learned that lesson somewhere, ultimately overcoming my innate Platonism and armoring myself against the aesthetic lures of neoclassical economics, so responsive to mathematical elegance

The art of polemic is evidently not lost. But science would be a lot easier, and much duller, if 'the data' were never consistent with more than one theory!

The second panel describes 'The Scientist as a Young Man'. His first job was with the City Managers' Association, permitting a taste of research into 'the science' of adminand so indifferent to data. istration. To most academics, administration is a mere chore, to be wistfully contrasted with research or teaching; but Simon succeeded in making a virtue of necessity. "I learned early that (in priniciple, at least) it gets easier, not harder, to administer as you move upward in an organization." As for teaching: "How does one instil curiosity into people? Without it, this 'educational' process is a continual struggle between a student who is trying to get by, and a teacher who is trying to catch him at it..." One of Simon's tasks at Illinois Tech was to teach courses on urban land economics and city planning administration to senior architects. There is a blistering attack on the architectural profession:

Architects are notoriously prone to design
buildings that are bid in at 40 percent over
the agreed budget. And they are notori-
ously inept with such prosaic details as
air-conditioning, energy efficiency, water-
proof roofs, and all manner of things their
clients and the inhabitants of their build-
ings consider important ... No society is
affluent enough to provide its architects
with all the steel and glass and concrete
they need to save their artistic souls.

The rebellious streak that surfaces here and elsewhere may have been partly responsible for the loyalty investigations to which its owner was occasionally subjected.

The rest of the second panel describes Herb Simon's move to Carnegie Tech in 1949 to help found the Graduate School of Industrial Administration, and the intellectual developments that finally culminated in the birth of artificial intelligence. The year 1955 was a watershed in Simon's scientific career. Until then a fairly conventional economist/political scientist, he transferred his empirical studies from the real world to the psychology laboratory and began to couch his theoretical ideas in the formal languages that are used for programming computers. By the end of that year Newell, Shaw and Simon had invented list-processing computer languages and had used them to create the Logic Theorist, a non-numerical program that took less than five minutes to find an elegant proof of proposition number 2.85 in Principia Mathematica. Russell's response to the news -

I am delighted by your example of the superiority of your machine to Whitehead and me. I quite appreciate your reasons for thinking that the facts should be concealed from schoolboys. How can one expect them to learn to do sums when they know that machines can do them better?

- might have turned the head of the most hard-boiled researcher:

Put less technically, if more boastfully, we invented a computer program capable of thinking non-numerically, and thereby solved the venerable mind-body problem, explaining how a system composed of matter can have the properties of mind.

The remainder of the book freewheels gently down from the intellectual summit, taking in 
the author's career in scientific politics, his Nobel prize and other honours - "I soon learned that one wins awards mainly for winning awards" - and various foreign adventures, including a memorable visit to Beijing that coincided with the Tiananmen Square uprising, thus flouting his newly enunciated travel theorem:

Anything that can be learned by a normal American adult on a trip to a foreign country (of less than one year's duration) can be learned more quickly, cheaply and easily by visiting the San Diego Public Library.

(My own travel theorem states that most of the world's troubles arise from people visiting places where they do not belong and interfering in matters that are not their business.)

The book is a mine of shrewd observations: on the need of students for their teachers' affection, and vice versa; on the roles of analysis and synthesis in science the latter much neglected; on the inexactness of the 'exact' sciences, at least in their application to practical problems, and on a common stumbling-block to interdisciplinary research:

\section{Nature or nurture}

\section{Peter Bryant}

The Origins of Exceptional Abilities. By Michael J. A. Howe. Blackwell: 1990. Pp.262. £35, \$39.95.

THE lives and achievements of talented people raise some interesting questions for psychologists, who would like to know the reasons for their extraordinary skills and would also like to find out if it is possible to teach more people to be gifted. These two questions are related, of course: if gifted people acquire their talents because of the experiences that they had during their childhood, it ought to be possible to provide other children with the same kind of experiences. The trouble is that it is usually very difficult to work out what are the causes of each gifted person's great success. Many gifted people work extremely hard at practising and improving their talents, and often, as children, receive a great deal of encouragement to do so from their parents and teachers. But we usually cannot tell whether these apparently propitious circumstances are the cause or the result of the person's talent. The young Mozart, for example, practised his music a great deal and he received much coaching from his father, but he also came from a musical family and it is quite possible that genetic factors played a considerable part in his extraordinary talents. It is also possible that he worked as hard as he did and received so much attention and encouragement because, for genetically determined reasons, he was unusually talented. We have no way of disentangling cause and effect.
I would not give a dollar to assist a typical political scientist to collaborate with a typical economist unless each one of them gave me a sworn statement that he would study seriously... the discipline of the other for at least a year.

As a historical document, the autobiography covers a period of astonishing intellectual ferment: the explosion of the information sciences after the Second World War, the resulting transformation of psychology by the information processing paradigm and the use of computer simulation for getting a grip on the behaviour of highly complex systems. Particularly welcome is Simon's support for the view that one working $\mathrm{AI}$ program is worth a hundred opinionated articles on the powers and limitations of machines or networks of one kind or another.

Models of My Life achieves most admirably the goal of the Sloan Foundation to "make the scientific experience and the excitement of discovery accessible to the general reader."

H. Christopher Longuet-Higgins is at the Laboratory of Experimental Psychology, University of Sussex, Brighton BN1 9QG, UK.

This means that anyone who sets out to convince us that the reasons for exceptional talents are environmental ones has a difficult task on his or her hands. Yet this is the position that Michael Howe adopts in The Origins of Exceptional Abilities. He does acknowledge from time to time that it is difficult to prove that the particular circumstances in which Darwin, Mozart, Sir Richard Burton and several others were brought up were responsible for their remarkable gifts, but he seems to be sure that the environmental explanation is the correct one. He writes,

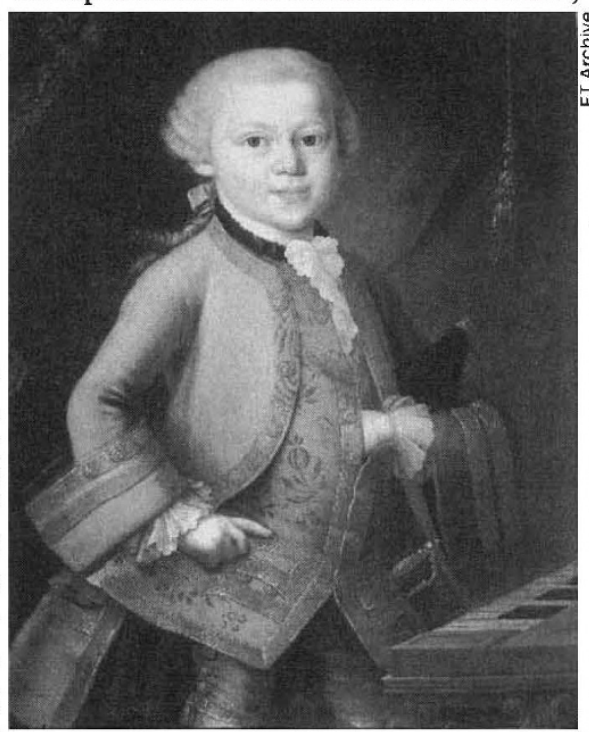

The child Mozart - was he born great or was greatness thrust upon him?

or course, at some length about the lives of these individuals and of several other people with exceptional talents, but he also marshals research on ordinary people to support his case.
His argument about the lives and particularly the childhood of exceptional people is unconvincing. His claim that they lived in unusual environments and had unusual experiences could only have any weight if it could be shown to be true. But we cannot rule out the possibility that other, less successful people were brought up in similar circumstances, and even if that were certain we would still have the chicken-and-egg problem of being uncertain whether the circumstances caused the talent or vice versa. The life histories of these extraordinary people always makes interesting reading, and they form the more interesting part of Howe's book, but the stories are not new and their relevance to our notions of intelligence have been discussed in more detail in books by Gruber, Gardner, Feldman and Treffert.

The work that Howe reviews on ordinary people is in the end no more persuasive. His main concern is to show that it is possible to influence people's skills by changing their experiences. Children, he argues, can be taught to read earlier, their motor skills can be improved, and their acquisition of language can be enhanced. All this is true but it has no obvious bearing on people with exceptional talents. Successful programmes for teaching reading do not produce exceptional readers - just children who can read. At times too, Howe seems to treat other people's views as hard evidence, provided that he shares those views. For example, he states that "Vygotsky showed that human cultures, internalised by children largely through the mediation of social interactions, not only provide access to skills and knowledge but also determine the fundamental sign systems that underlie knowledge". This is certainly what the Russian psychologist thought to be the case, but he never 'showed' that his theory was right, and in fact did very little in the way of empirical research.

Howe's charitable assessment of those who take the same position as his own contrasts strongly with his approach to other views with which he disagrees. "Far too often", he writes, "people have accepted uncritically beliefs about the importance of this or that factor simply because they seem plausible, or appear to be true or are widely considered by others to be true." But, disappointingly, he does not go on to identify these 'people' or to tell us exactly what their uncritical beliefs are.

The Origin of Exceptional Abilities raises an important and interesting question and provides a firm, but in the end quite unconvincing, answer. In fact no definite answer is possible at the moment. Until one is, we will need, and we still have to wait for, a fair and reasoned account of the evidence for and against all the plausible hypotheses about the reasons why some people acquire astonishing talents and the rest of us do not.

Peter Bryant is in the Department of Experimental Psychology, South Parks Road, Oxford OX1 3UD, UK. 